\title{
脳動脈瘤の同胞例
}

\section{後藤 恒夫・古和田正悦}

\section{Intracranial Aneurysms found in Three out of Eight Siblings}

\author{
Tsuneo Goto and Masayoshi KowadA \\ Neurosurgical Service, Akita University, Akita
}

\begin{abstract}
Intracranial aneurysms found in three out of eight siblings in one family are presented, with a review of ninety-six sibling cases in the literature.

The eight siblings comprised four brothers and four sisters. Patients suffering from subarachnoid hemorrhage were the third sister, aged 57 years, and the eldest brother, aged 65 years. They were successfully treated by clipping of the ruptured aneurysms. The eldest sister, aged 72 years, was shown to have an unruptured aneurysm by angiography.

Ninety-nine reported cases of sibling aneurysms including the present three cases were analyzed from the view points of familial relationship, age at onset, sex incidence, and location of aneurysm. Compared with intracranial aneurysms in the general population, aneurysms in sibling cases had a lower incidence of anterior cerebral or anterior communicating artery aneurysms, and a higher incidence of middle cerebral artery aneurysms. In cases where more than two siblings suffered from subarachnoid hemorrhage, other members were reported to have an increased risk of intracranial aneurysm. An angiographical investigation should be considered in such cases.
\end{abstract}

Key words: familial occurrence, intracranial aneurysm, angiography

\section{Iはじめに}

脳動脈瘤の家族内発生例は, 1942年に $O^{\prime}$ Brien $^{17}$ が一卵 性双生児の中大脳動脈瘤を報告して以来, 文献的に現在ま で61家族138例が報告されている11,14,20,22,23\}，家族内発生例 は比較的若年者に多発し，中大脳動脈瘤の頻度が高く，前 交通動脈瘤の頻度は低いことなどが指摘されてい $3^{3.14 .18 !}$.

最近我々は, 同胞 8 人の5ち3人に脳動脈瘤が確認され た很例学経験したので, 脳動脈瘤の家族内発生例のうちで も同泡例に関して若干の文献的考察を加えて報告する。

\section{II 症例}

今回経娩した拝例の家系をFig. 1に示寸。両親上次女

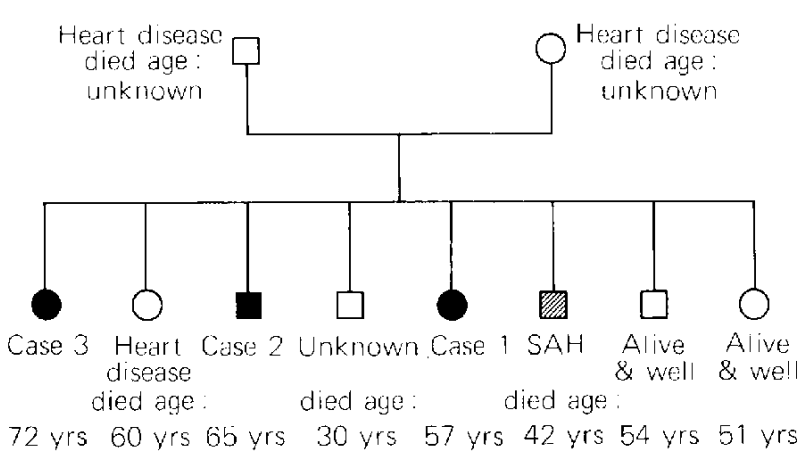

Fig. 1 The family tree. Squares indicate male and circles female. Solid black symbols are intracranial aneurysm cases. Hatch marking is a case in which intracranial aneurysm is suspected.
秋由大学脳神释外科

Address reprint requests to: T. Goto, M.D., Ncurosurgical Scrvice, Akita University, 1-1-1 Hondo, Akita 010.

栄稿 1985年1月14日受理 1985年6月4日 
は心疾忠で死亡し，次男る 30 才で死亡しているがその死风 は不明である。脳動脈瘤が確認されたのは長女(〈泟例 $3\rangle)$ ，長男(〈症例 2〉)，三女(〈将例 1〉)の3人である。东 た，三男もクモ膜ト出血で死亡しているが，脳血管撮影や 剖桱汢行わ机ていないので詳細は不明である。四男と四女 住健康てする。

<症例 $1>57 才$, 女性 (三女)

主訴 : 頭痛, 嘔叶

既往歴：10年前より高血压症で治燎を受けていた。

現病歴：1982年4月19日，農作策中に突然頭痛上嘔叶を 培え，近医でクモ膜下出血を疑われ，約 2 時間後に当科に 入院した。

入院後経過：入院時，意識は200( III-3万式)で尿失禁が

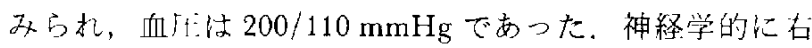
万人の共同偏視がみられたほか性，項部強直や運動麻痺な どは哂められなかった，CTにて両側シルビウス裂，半球 間裂，媨底槽の伀汎なクモ膜下出血の所見がみられ( Fig. 2A)，稱血管撮影で法動脈瘤が前交通動脈に 1 個，左中大 脳動㟲 $\mathrm{M}_{1}$ 部に 2 個造影された(Fig. 2B).

意浅が注隹清明となった4月30日に根治手術を行った。 両側润䫓開頭で半球間㤠より前交通動脈瘤に接近すると, 脳動脈瘤周国には㠜!地塊が充渵し，クモ膜の肥厚および瘾 着が将明て，破裂脸動脈瘤と考えられた，脳動脈瘤頸部は 広羍でクリッピング不能なため，前交通動脈をトラップし た。次に，左側シルビウス裂より中大敛動脈㨨に接近して 活位部の動脈瘤をクリップした。遠位部のものはわずかに
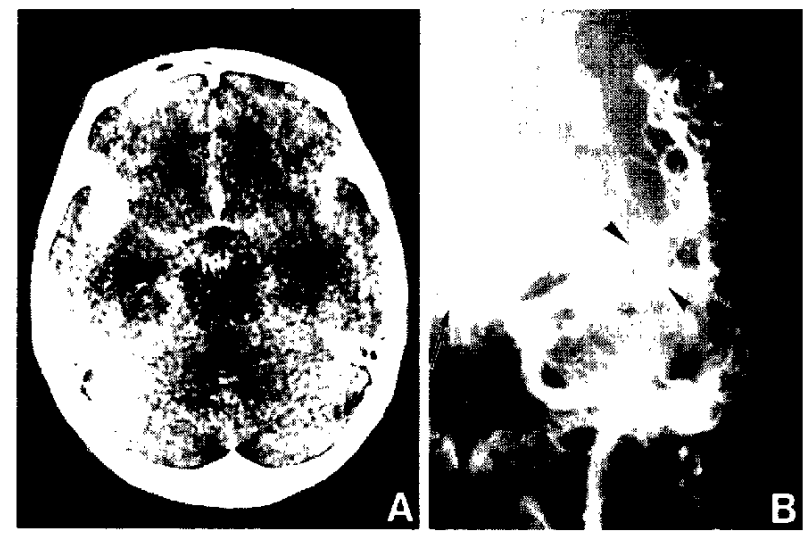

Fig. 2 Case 1. A: Computerized tomography (CT) scan reveals subarachnoid hemorrhage in the bilateral Sylvian fissure, the interhemispheric fissure, and the basal cistern. B: Left carotid angiogram shows three isolated ancurysms, located at the anterior communicating artery (arrow) and the middle cerebral artery (arrowheads).
ドーム状に突出していたのでこれを筋附片でコーティン グした。しかし，術後に正常圧水頭症索併したため，5 月7日に脳穻一腹腔短絡術を行った。その後の経過は順調 だ，10月10Hに独歩退院した。

<症例 $2>65 才 ，$ 男性（長男)

主訴：站痛, 否片麻㾝

既往歴：20年前と10年前に胃潰瘍で入院した。

現病歴：1984年 2 月 5 Hから軽度の前頭部痛で鎮痛剂を 服用していたが，2月19日夜半に突然激しい頭痛と右片麻 疩在訴元，䄪 1 時間後に入院した。

入院媵経過 : 入院時, 意識はほぼ清明で, 㪕度の項部強 自上在片麻痒が認められ，血压は $210 / 110 \mathrm{mmHg}$ であっ た，CTではクモ膜卜出血の所見呈しており，半球間裂 と右前頭葉内に高吸收域が認められ，第三脳室上雨側側脳 窒は軽度に搪大していた（Fig．3A)。また，脳血管撮影で 朔交通動哌に後上万に突出寸る動脈瘤が造影され，右前大 兴動脈 $\mathrm{A}_{1}$ 部に血管攣縮がみられた(Fig. 3B)．脸血管撮影 谣に意識は100まで低下し，また多龺の消化管出血があっ たため，保存的に治療した。

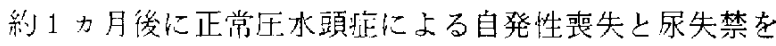
きたしたが，意識レベルは 2 まで回復したので4月16日に 根治千術を行った。両側前頭開頭で半球間裂より兴動脈瘤 に達してこれをクリップした。正常龙水頭症に刘しては， 5 月 7 日に脸室一腹腔短絡術を行った。術徯, 自発性表失 上氺失禁江改善され，右片麻疩もしだいに軽快し，8月7 日に独歩退院した。
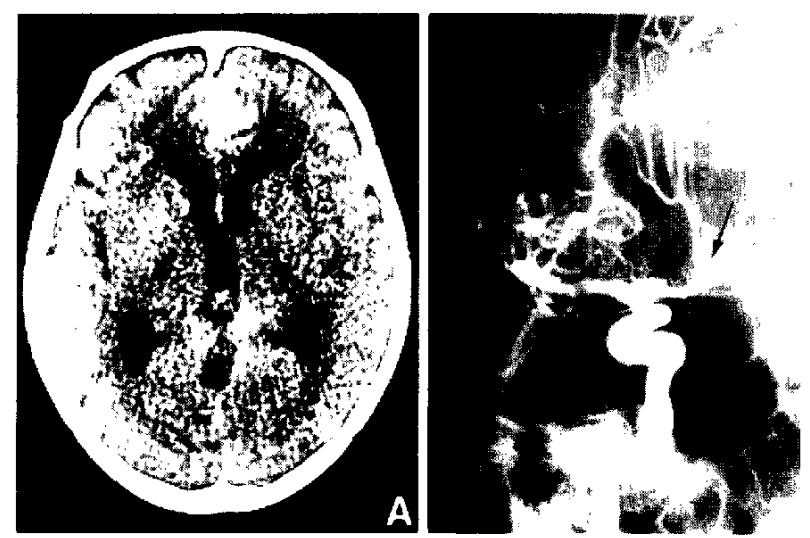

Fig. 3 Case 2. A: CT scan reveals subarachnoid hemorrhage in the interhemispheric fissure and an intracerebral hematoma in the right frontal lobe. B: Right carotid angiogram shows a saccular aneurysm at the anterior communicating artery (arrow), and angiospasm at the $A_{1}$ portion of the right anterior cerebral artery. 


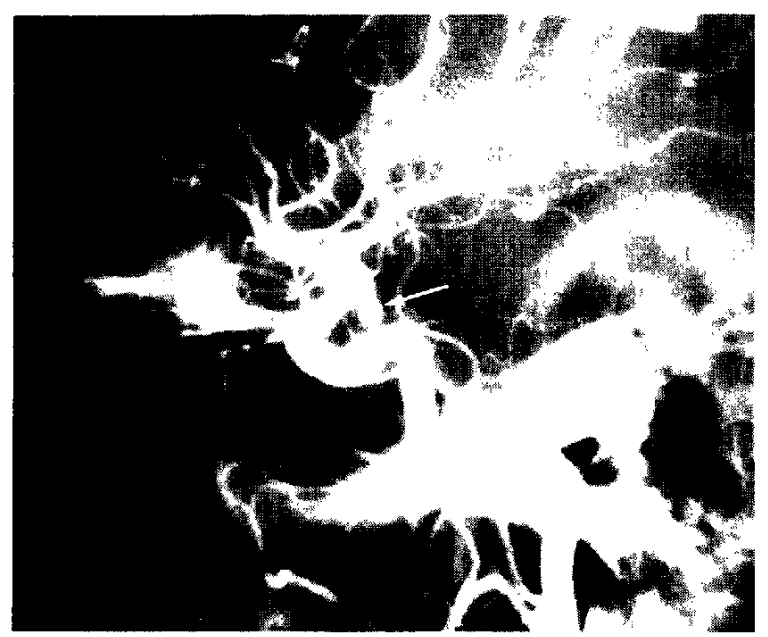

Fig. 4 Left carotid angiogram of Case 3 shows a saccular aneurysm at the left internal carotid artery (arrow)

<症例 $3>72$ 才, 女性 (長发)

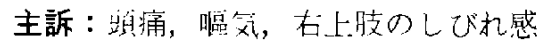

既往歴：10年前上り高欰圧痰で治療在受けていた。

現病歴：1984年 2 月顷加方，嘔気を伴う前頚部のしかつ けられる上うな痛みと, 右上肢のしびれ感を訴えるように なった，同胞 3 人がクモ膜下出血に罹患していることから，

3 月16日に精榃のため入院した。

入院後経過：入院時，神経学的に異常所見住認的ら九な かった，兴血管撮影にて，左内頝動脈に媵下才に突出寸る 動脈瘤が华影された（Fig. 4)。しかし，高路であり家族む 手術老希望しなかったため3月17日に退院し，現在外来で 経過観察中である.

\section{III 考察}

家族内脳動脈榴は，O'Brien(1942年)17が一即性双生児 に㧍ける中人䏚動脈瘤を初めて報告し, Chambersら (1954年) $)^{5}$ が㨫動脈溜の発生において先天性説の根拠とし て以米，現在志で自騃例含力て62家族141例11,14,20,22,23i が報告されている。これらの62家族について血縁関係昰要 とめてみる上，同胞39組，親子21組で，そのほかに姪抢よ び甥の関俰がそれぞ机 1 組である。同胞例の内谷は姉妹が 13䋁，兄弟が8組，性差のあるものが18組で，一畉性双生 罗は姉妹13組のうち3組，兄弟8 組のうち1組に双られ る。虫た親子関媇では，母·息子9 組，母・娘 6 組，父・ 娘 3 組，父・息子 1 組，父・了供详 2 組である. Sakai

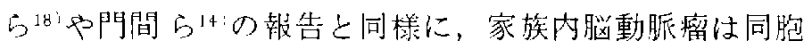
に多く，から姉妹関倸であり，親子では母.子供に多い傾 向が窺える。
Table 1 Age distribution in eighty-eight sibling cases of intracranial aneurysm

\begin{tabular}{ccc}
\hline Age in years & No. of cases & $\%$ \\
\hline $0-9$ & 0 & 0 \\
$10-19$ & 0 & 0 \\
$20-29$ & 15 & 17.0 \\
$30-39$ & 19 & 21.6 \\
$40-49$ & 27 & 30.7 \\
$50-59$ & 21 & 23.9 \\
$60-69$ & 5 & 5.7 \\
$70-$ & 1 & 1.1 \\
\hline
\end{tabular}

Table 2 Site distribution of intracranial aneurysms in sibling cases

\begin{tabular}{lcc}
\hline Site & $\begin{array}{c}\text { Sibling aneurysms } \\
(\%)\end{array}$ & $\begin{array}{c}\text { Co-operative study } \\
(\%)\end{array}$ \\
\hline ICA & 37.7 & 38.6 \\
ACA \& AcomA & 19.3 & 28.0 \\
MCA & 35.1 & 17.1 \\
Posterior circulation * & 7.0 & 11.4 \\
Others & 0.9 & 4.8 \\
\hline
\end{tabular}

*Posterior circulation includes vertebral, basilar, and posterior cerebral arteries. ICA indicates internal carotid artery; ACA, anterior cerebral artery; AcomA, anterior communicating arterv; MCA, middle cerebral artery.

同肥例は99例1,79,11,14,15,20.22 で，そのうち記載の明確な 88侧の発疜年齢を Table 1 に示寸，こ机までの報告による と，家族内発生例では発症年齢のピークが30〜40才台で, 比較的华华者に発生寸る傾向が指摘されている3 方，同胞例のみ集䛉てみると，50才台の占める割合が $23.9 \%$ 上高く，発症年齢のピークは非家族例と同様に40 50 才台である。性別では男性38例 (43.2\%)，女性50例 $(56.8 \%)$ で，处性にやや多い。专た，同胞例に招ける脳動 搌瘤で，部位の明らかなものは91例である。そのうち単発 珄は72例( $79.1 \%)$ ，多発性が19例(20.9\%)である。これら の発生部位別頻度を，米国に抺ける脳動脈溜集計： と対比 してTable 2 に示す。内頸動脈瘤の頻度は非家族例とほぼ 同样であるが，同胞例では中大脳動脈瘤が $35.1 \%$ であり， 高い頻度で発生している。これに対して，前大脳動脈瘤お よび角交通動脈留の頻度は19.3\%である、このことは家族 肉脳動脈瘤に関する他の報告3,14,18)でも指摘されている。

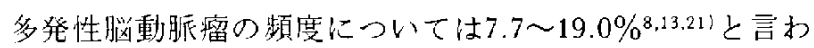
れているが，间胞例でみると $20.4 \%$ であり比較的高い傾向 にある。3 同胞以上に発生した脳動脈瘤は，自験例を含め 
て 7 家族27例が報告されている4,6,7,9,18,22!．才なうち，3 同 胞に発生した例は白験例以外に3家族 ${ }^{4,18,22)} ， 4$ 同胞が 2

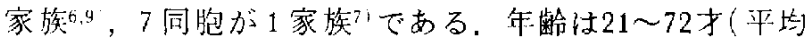
42 才) で，性:别は男性11例，女性16例である。主た脸動脈 㨨は合計38個で，その部位別頻度は内頸動脈15倜 $(39.5 \%)$ ，中大脳動脈14個 $(36.8 \%)$ ，前大脳動脈打よび㓩 父通動眽 8 個 (21.1\%)，椎骨動脈 1 倜 $(2.6 \%)$ で，多発性 脳動脈瘤が 7 例 $(25.9 \%)$ にみられる。

これらの報告で注月されるのは，6家族の5ち3家族に おいて無佂状例に兴血管撮影が行われた結果，未破裂脸動 脈瘤が 6 例に確認されていることである

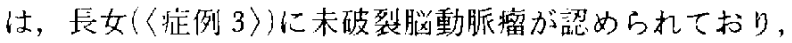
報告した 3 症例のほかにも51人(三男)が脳動脈鹰破裂に よると思われるクモ膜下出血で死ししている.同胞のうち 2 人以上に脳動脈㨨の発生が確認された場合には，他の同 肘にも未破裂脳動脈瘤の存在している可能性が高く，脸血 管撮影在皘極的に行って娭索する必要があるとすら言われ ている1.29,11。このような扯例に遭遇した場台には，家族 とよく相荻のト，残りの同胞にも検查を勧め，もしも未破

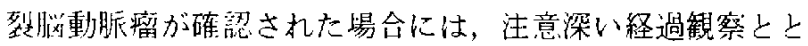
もに，未破裂脳動脈瘤の自然経過 ${ }^{10,16)}$ および手術成績 ${ }^{12.19}$ を考㶨して自達手術をむ针めるべきであるう。

\section{IV 結 語}

8 人のうち3人に発牛した脳動脈瘤の同胞例を経験した ので，家族內脳動脈瘤の同胞例について，血縁関倸や発将

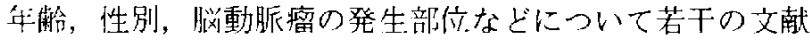
时考察を行い報告した。

\section{文献}

1) Acosta-Rua GJ: Familial incidence of ruptured intracranial aneurysms. Report of 12 cases. Arch Neurol 35: 675-677, 1978

2 Ambrosetto P, Galassi E: Familial occurrence of multiple intracranial aneurysms: Case reports and review of the literature. Acta Neurochir (Wien) 56: 233-238, 1981

3) Andrews RJ: Intracranial aneurysms: Characteristics of aneurysms in siblings (Letter). $N$ Engl J Med 297: 115, 1977

4 Beumont PJV: The familial occurrence of berry aneurysm. $J$ Neurol Neurosurg Psychial 31: 399-402, 1968

5) Chambers WR, Harper BF, Simpson JR: Familial incidence of congenital cerebra] aneurysms of cerebral arteries: Report of cases of ruptured aneurysm in father and son. JAMA 22: 358-359, 1954

6) Edelsohn L, Caplan L, Rosenbaum AE: Familial aneurysms and infundibular widening. Neurology (Minneap) 22: 1056-1060, 1972

7) Fox JL: Familial intracranial aneurysms: Case report. $J$ Neurosurg 57: 416-417, 1982

8) Fox JI: Intracranial Aneurysms. Berlin, Springer, 1983, pp 19-62

9) Hashimoto I: Familial intracranial aneurysms and cerebral vascular anomalies. $J$ Neurosurg 46: 419-427, 1977

10) Heiskanen $O$ : Risk of bleeding from unruptured aneurysms in cases with multiple intracranial aneurysms. I Neurosurg 55: 524526,1981

11) Jain KK: Familial intracranial aneurysms. Acta Neurochir (Wien) 30:129-137, 1974

12) Jain KK: Surgery of intact intracranial aneurysms. J Neurosurg 40: $495-498,1974$

13) Locksley HB, Sahs AL, Knowler L: Report on the cooperative study of intracranial aneurysms and subarachnoid hemorrhage. Section II. General survey of cases in the central registry and characteristics of the sample population. $J$ Neurosurg 24: 922-932, 1966

14)門間文行，古和田正悦，莱地显次，玉川芳春：脳動脈瘠の 家族内発牛例。診断上治燎 67: 1001-1005, 1979

15) Morooka Y, Waga S: Familial intracranial aneurysms: Report of four families. Surg Neurol 19: 260-262, 1983

16) Mount LA, Brismann R: Treatment of multiple intracranial aneurysms. J Neurosurg 35: 291-295, 1971

17) O'Brien JG: Subarachnoid hemorrhage in identical twins. Brit Med J 1: 607-608, 1942

18) Sakai N, Sakata K, Yamada H, Yamamoto M, Aiba T, Takeda F: Familial occurrence of intracranial aneurysms. Surg Neurol 2: $25-29,1974$

19) Salazar JK: Surgical treatment of asymptomatic and incidental intracranial aneurysms. $J$ Neurosurg 53: 20-21, 1980

20) Shigemori M, Shirahama M, Tokutomi T, Hara K: Familial intracranial ancurysms associated with rare cerebrovascular anomalics. Case reports. Neurol Med Chir (Tokyo) 22: 77-80, 1982

21) Suzuki J, Hori S, Sakurai Y: Intracranial aneurysms in the neurosurgical clinics in Japan. $J$ Neurosurg 10: 288-294, 1960

22) Verdura J, Resnikaff S, Rosenthal J, Gardenas J: Familial intracranial aneurysms, with two occurring at the distal anterior cerebral artery. Neurosurgery 12: 214-216, 1983

23）安时恒男，菅湶得，古和田证悦，後藤博美：ほぼ问時期 に発拕した脳動脈溜の母親・娘例一家族内発生例の文献的考 察一。譇断上治療 72: 159-162, 1984

〔剔刷請求先：干010 秋田市本道1-1-1，秋田大学脳种释外科， 得藤恒太门 